\title{
The Association of Quality of Life and Personality Characteristics with Adolescent Metabolic Syndrome: a Cohort Study
}

xiaohua liang ( $\nabla$ xiaohualiang@hospital.cqmu.edu.cn )

Children's Hospital of Chongqing Medical University https://orcid.org/0000-0003-3867-9779

Peng Zhang

CDC of Jiulongpo District

Shunqing Luo

Chongqing Medical University Affiliated Children's Hospital

Guifang Zhang

Chongqing Medical University Affiliated Children's Hospital

Xian Tang

Chongqing Medical University Affiliated Children's Hospital

Lingjuan Liu

Chongqing Medical University Affiliated Children's Hospital

\section{Research}

Keywords: Quality of Life, Personality Traits, Adolescent, Metabolic Syndrome, Cohort Study

Posted Date: January 5th, 2021

DOI: https://doi.org/10.21203/rs.3.rs-69278/v2

License: (c) (1) This work is licensed under a Creative Commons Attribution 4.0 International License. Read Full License

Version of Record: A version of this preprint was published at Health and Quality of Life Outcomes on June 8th, 2021. See the published version at https://doi.org/10.1186/s12955-021-01797-7. 


\section{Abstract}

Background: An increased prevalence of adolescent metabolic syndrome (MS) is associated with adulthood cardiovascular diseases. This study aimed to explore the potential relationship of quality of life (QoL) and personality traits with adolescent MS.

Methods区A total of 1961 participants from Chongqing with an average age of 11.68 years from a cohort study established in 2014 and followed through 2019 were included. QoL information, Eysenck's personality questionnaire and MS components were collected.

Results: The prevalence of adolescent MS was 4.69\% (95\% confidence interval, 3.84\%-5.72\%). A higher QoL domain score of physical activity ability (PAA) was a protective factor for both MS and MS score (all $P<0.01$ ), which was mainly negatively correlated with central obesity, diastolic blood pressure (DBP) and triglycerides levels, as well as positively correlated with high density lipoprotein cholesterol (HDL-C) level. The total QoL score was negatively correlated with triglycerides level and positively correlated with DBP (all $P<0.01)$. High extraversion personality score was a protective factor against adolescent MS $(P=0.04)$ and MS score $(P<0.05)$, which was mainly negatively correlated with waist circumference, systolic blood pressure and TGs, and positively correlated with HDLC (all $P \leq 0.01)$.

Conclusions: QoL score and extraversion personality score were independent protective factors against both MS prevalence and MS score, suggesting that community intervention to improve the QoL and psychological health of children is essential.

\section{Introduction}

The increased prevalence of adolescent metabolic syndrome (MS) and MS components severity scores were independent predictors of adulthood cardiovascular diseases (CVDs) [1,2]. MS components in adolescents includes central obesity, elevated triglycerides (TGs), reduced high density lipoprotein cholesterol (HDL-C), elevated blood pressure and impaired fasting glucose. The prevalence of MS among adolescents ranged from $3.5 \%$ to $11.2 \%$ according to different region and different diagnostic criteria $[3,4]$. Current studies $[5,6]$ have found that shared genetic and environmental factors, family history of CVD and obesity, maternal gestational diabetes [7], low birth weight, early adiposity, social economic status (SES)[8], short duration of sleep[9], excessive screen time, dietary factors, low physical activity, and tobacco smoke exposure were potential risk factors for adolescent MS or MS components. The literature consistently demonstrates evidence for the association of physical health risks and socioeconomic status with adolescent MS or its' components; however, the association of health-related quality of life $(\mathrm{QoL})$ and personality traits with adolescent MS should also gain the attention of researchers.

Limited studies[10] have illustrated the inverse relationship of QoL with MS or MS components mainly in adults, and the conclusions were controversial. However, the majority of studies showed that the association existed only in women[11], or existed only in subjects with depression [12]. Previous studies revealed that the QoL domain scores of physical health[13] and social relationships[14], but not those of the mental health and perceived stress domains, were correlated with MS. Moreover, the impact factors of QoL were age, obesity, puberty development stage, SES, physical activity[15, 16] and unhealthy dietary behaviour[17], which were also correlated with MS. In addition, one community obesity intervention study[18] revealed that the control of obesity was associated with QoL improvement. These studies, taken together, suggest that QoL may have significant effects on MS, but evidence in children and adolescents is scarce. Therefore, it is urgent to explore the association of QoL with adolescent MS and reveal which QoL domains have salient effects.

Personality traits may impact MS and its components, although few studies have investigated this association. One study showed that children with obesity may experience several psycho-social problems[19]. A study found that extraverted personality is positively correlated with TG, fasting blood-glucose (FBG) and MS score in adults [20]. However, to our knowledge, there are no studies exploring the correlation between personality traits and MS in adolescents, and the personality traits tend to be stable over time and consistent across situations[21]. Therefore, the personality traits may impact the prevalence of MS among children and adolescents, which need to be illustrated.

In this study, we investigated, whether QoL scores were inversely correlated with adolescent MS and MS components, which domains have salient effects, and whether the association was independent of age, sex, region and other variables. We investigated whether personality traits (extraversion, neuroticism, psychoticism) were associated with MS and MS components, and whether the association was independent of the influence of sex, age and other factors.

\section{Methods}

\section{Subjects}

Two stage stratified cluster sampling was used to include participants from two counties in Chongqing that represent urban and rural areas; then, two regions per county were randomly selected, and 3067 children (including 2808 children who entered the cohort in 2014 , and 130 and 129 children who transferred to the target schools in 2015 and 2019, respectively) were ultimately informed and included if they met the inclusion criteria. Participants who met all the following criteria were recruited: (1) aged between 6 and 9 years in 2014, (2) resided in the target region for more than 6 months, (3) did not have serious diseases (e.g., nephropathy, cardiovascular disease or cancer), and (4) consent was provided by the parents and children for participation. The sample size was calculated with the following parameters: a level of 0.05 , power of $90 \%$, prevalence of MS components of $15 \%$ and prevalence in the population of $10 \%$, using the formula. Assuming an attrition rate of 20\%, 1859 participants were needed, and 1961 subjects were ultimately included in this study (as shown in Figure 1). At baseline, all participants completed the SES and family health history questionnaires and were recruited mainly from grade one and grade two from primary public-schools screening of children whose families were interested in health research. The questionnaires were administered and collected by the teachers. The Institutional Review Board at the Children's Hospital of Chongqing Medical University provided approval for the study. Informed consent was provided by all subjects and parents/guardians.

\section{Demographic Variables}


Demographic information, SES and prenatal variables, including maternal preconception obesity, increased body mass index (BMI) of the mother during pregnancy, birth with caesarean section, premature delivery ( $<37$ weeks), birth weight, breastfeeding, gestational hypertension (GH) and gestational diabetes were collected.

The validity and reliability of the demographic questionnaire were checked and are described in detail in a previous publication[22]. The demographic questionnaire was completed by the parents or guardians of the children after standard training by the research group, and detailed instructions regarding the questionnaire were given to the parents or guardians.

\section{Physical Examination}

Anthropometric measurements were conducted both in 2014 and in 2019 by well-trained pediatric nurses, and the protocol for these measurements was described in a previous publication[22]. Waist circumference (WC) was used as an alternative measure of central adiposity. Hip circumference was measured twice horizontally at the level of the pubic symphysis in the front and the gluteus maximus in the back, with the participant standing upright and with their legs together and placing their arms naturally at their sides; the mean value was used.

Blood pressure (BP) was measured on three separate occasions with an OMRON arm-type electronic sphygmomanometer (HEM7051) using an appropriately sized BP cuff placed on the subject's right arm, with the subject in a seated position, as described in detail in a previous publication[22].

\section{Biochemical Indexes}

The biochemical markers of FBG, HDL-C, TG, low density lipoprotein cholesterol (LDL), and total cholesterol (TC) were measured in 2014 and 2019 . Venous blood $(3 \mathrm{ml}$ ) was drawn from each subject in the morning after at least 12 hours of fasting and 24 hours of abstaining from high-fat and spicy foods. The biochemical markers were measured within 2 hours after venous blood was drawn using the protocol introduced in detail in our previous publication [22].

\section{Measurement of QoL and Eysenck's Personality Questionnaire (EPQ)}

The QoL questionnaire for adolescents consists of 49 items, including 4 factors (psychosocial function, physical and mental health, living environment and QoL satisfaction) and 13 dimensions, such as self-satisfaction, relationship of teacher and pupil, physical feeling, companionship, parenthood, physical activity ability(PAA), learning ability and attitude, self-esteem, negative emotion, attitude towards completing homework, opportunity for activity, living convenience and others (picky-eating and surroundings), as detailed in supplementary figure 1 . The order of presentation of the 49 items was randomized. Children rated the statements on a 4-point scale, and the direction of response (positive or negative) varied item by item to limit response bias. Individual item values were recoded prior to analysis such that the direction was consistent. Responses were summed and normalized according to the age-, sex- and regionspecific norms of China into a score $T$ (range, $0-100)$, using the function $T=50+(X-M) / S D \times 10$, with higher scores suggesting a better QoL status [23].

The Chinese version of the Eysenck personality questionnaire[24] consisted of 88 items scored on a 2-point scale (for positive items NO=0 and YES=1), including 4 domains: extraversion (E) (25 items), neuroticism (N) (23 items), psychoticism (P) (18 items), and lie scales (L) (22 items). High scorers on the E scale indicate sociable, exciting, pleasurable, carefree, and aggressive characteristics. A higher score on the $\mathrm{N}$ scale is more likely to indicate a worried and moody person who tends to suffer from emotional and psychosomatic disorders. The P scale was designed to measure behaviour patterns that may be considered schizoid or psychopathic in extreme cases. The $L$ scale assesses response bias. Items in the $E, N, P$ and $L$ domains are summed and normalized to the age- and sex-specific norm into a score ranging from 0 to 100 using the function $T=50+(X-M) / S D \times 10$. People are defined as middle type, tendency type and typical type based on $\mathrm{T}$ score ( $\mathrm{E}$ and $\mathrm{N}$ ) ranges of $43.3-56.7,38.5-43.3$ or $56.7-61.5$, and $<38.5$ or $>61.5$, respectively. People were considered to have a psychotic personality if the $T$ score of the $P$ domain was $>56.7$. We considered the response regarding personality traits invalid if the $T$ score of the $L$ domain was $>70$.

Fifty samples were required to complete the same questionnaire twice within a one-week interval to check the validity and reliability of the QoL and Eysenck's Personality Questionnaires before our formal survey. QoL and Eysenck's Personality Questionnaires were completed by the adolescents after a standard training.

\section{Diagnostic Criteria}

The MS of adolescents was defined by the presence of three or more of the following five components [5, 25]: $(1)$ central obesity defined as $\geq 90$ th percentile for age and gender criteria in China[26]; (2) elevated systolic and/or diastolic blood pressure $\geq 90$ th percentile for age, sex and height (according to the study by Jie Mi[27]); (3) hypertriglyceridemia defined as TG $\geq 1.24 \mathrm{mmol} / \mathrm{L}$; (4) low serum HDL-C defined as HDL-C $\leq 1.03 \mathrm{mmol} / \mathrm{L}$, and (5) impaired fasting glucose (IFG) defined as FBG $\geq 5.6 \mathrm{mmol} / \mathrm{L}$. Next, individual MS score was calculated as the sum of the number of MS components present (range, $0-5$ ).

The definitions of size for gestational age were based on the global reference for foetal-weight and birthweight percentiles[28]: birth weight at or above the 90th percentile indicated large for gestational age (LGA), and birth weight less than the 10th percentile indicated small for gestational age (SGA), using the parameters of mean birthweight at 40.5 weeks of $3332.93 \mathrm{~g}$ and a variation coefficient of $14.36 \%$. Maternal overweight and obesity before pregnancy were indicated by a BMI of $24 \sim 27.9 \mathrm{~kg} / \mathrm{m} 2$ and $\geq 28 \mathrm{~kg} / \mathrm{m} 2$, respectively, and a BMI $<18.5 \mathrm{~kg} / \mathrm{m} 2$ was defined as a low BMI [29]. According to guidelines of the Institute of Medicine (IOM) for maternal pregnancy weight gain [30], the recommendation is for underweight, normal weight, overweight, and obese women to gain $12.5-18.0 \mathrm{~kg}, 11.5-16.0 \mathrm{~kg}, 7.0-11.5 \mathrm{~kg}$, and 5.0-9.0 kg, respectively; if weight gain exceeded that range, weight gain was defined as "above IOM guidelines", and if weight gain was below that range, was defined as "below the IOM guidelines".

\section{Statistical Analyses}


Differences in anthropometric measures, serum biochemical indexes, QoL and personality score among three groups were assessed using ANOVA, and posthoc comparison was performed using Student-Newman-Keuls (SNK) test. The $\chi^{2}$ test was used to test the difference in the component ratio of potential risk factors of MS components. Logistic regression model was performed using diagnosed MS components or MS as the dependent variables with QoL and personality traits, as independent variables, and adjusted for covariables. In addition, a generalized linear model (GLM) was used to analyse the correlation of QoL and personality traits scores with MS components levels and MS score, adjusted covariables.

The data analysis was conducted using SAS 9.4 software (Copyright @ 2020 SAS Institute Inc. Cary, NC, USA). A significant difference was defined by an a level of 0.05 .

\section{Results}

\section{General characteristics}

The general characteristics of the subjects are shown in Table 1. A total of 1961 samples were included, with a follow up rate of 63.94\% (1961/3067). The mean age was $11.68 \pm 0.60$ years $(7.26 \pm 0.59$ years at baseline), and $52.01 \%(1,020 / 1,961)$ were males. The prevalence of adolescent MS was $4.69 \%$ (92/1961), and the prevalence of MS components were 21.83\% (428/1961), 25.45\% (499/1961), 9.28\% (182/1961), 9.79\% (192/1961) and 1.53\% (30/1961) for central obesity, elevated TG, reduced HDL-C, elevated BP, and IFG, respectively. Anthropometric measures; biochemical indexes; MS components; perinatal, and SES variables; QoL score; and personality characteristics among the MS groups are shown in Table 1. Anthropometric measures of elevated BMI, WC, systolic blood pressure (SBP) and diastolic blood pressure (DBP) and biochemical indexes of FBG, TG and LDL-C, as well as decreased HDL-C measured in 2014 were risk factors of adolescent MS in 2019. Age, region, foetal weight of pregnancy week and mother's education level, which were adjusted in the multivariable analysis, showed significant difference between the three groups (no MS component, 1 2 MS components and MS) (all $P<0.05$ ).

Table 1 displays the QoL and personality traits scores of children with different MS component score. Adolescents with MS had lower QoL domain score of PAA, activity opportunity and other (picky-eating and surroundings) than their counterparts with no or $1-2 \mathrm{MS}$ components $(P<0.01, P=0.03$ and $P<0.01)$. In addition, the extraversion score of personality traits was decreased in children with MS compared with their counterparts with no or 1-2 MS components $(P=0.05)$.

\section{Relationship of elevated MS components with QoL and personality scores}

The results of the Logistic regression analysis in Table 2 demonstrate the relationship of MS components in 2014 with QoL and personality traits in 2019 after adjusting for age, sex, region, foetal weight of pregnancy week and mother's education level. Central obesity in 2014 induced a lower QoL domain score of PAA $(P<0.01)$ and living environment factor score of QoL $(P<0.01)$, while it was positively correlated with higher neuroticism traits in adolescence $(P=0.03)$. Elevated BP in childhood was inversely correlated with QoL domain scores of companionships $(P=0.05)$. In addition, elevated TG in childhood caused lower domain score of self-satisfaction $(P=0.01)$ and QoL satisfaction $(P=0.05)$. Decreased HDL in childhood correlated with lower QoL domain scores of physical feeling and negative emotion, as well as physical and mental health factor score in adolescents (all $P<0.05)$. IFG in childhood was positively correlated with QoL domain scores of self-satisfaction, parenthood, negative emotion, QoL satisfaction factor scores and the total QoL score (all $P<0.05)$, and it was inversely correlated with neuroticism traits $(P=0.02)$.

The association of elevated MS components in 2019 with adolescent QoL and personality traits in 2019 is showed in Table 2. An elevated domain score of PAA and living environment factor score were protective factors for central obesity (all $P<0.01$ ). However, the domain score of other (picky-eating and surroundings) was positively correlated with central obesity, elevated BP and decreased HDL (all $P<0.05$ ). The QoL domain scores of self-satisfaction, physical feeling, negative emotion and factor scores of physical and mental health and quality of life satisfaction were positively correlated with elevated BP. In contrast, personality traits scores of extraversion $(P=0.02)$ were negatively correlated with elevated BP. In addition, elevated domain score of QoL of selfsatisfaction, physical feeling, parenthood, PAA, negative emotion, factor score of physical and mental health and total score of QoL were correlated with elevated TG, while neuroticism score was positively correlated with elevated TG (all $P<0.05)$. The domain scores of physical feeling $(P=0.04)$ and activity opportunity $(P=0.03)$ were positively correlated with IFG.

Sub-group analyses of participates without MS components in 2014 are shown in Table 2. The results showed that PAA and living environment were negatively correlated with central obesity (all $P<0.01)$, companionship was positively correlated with elevated $\mathrm{BP}(\mathrm{P}=0.04)$, and activity opportunity was positively correlated with IFG $(P=0.02)$. Furthermore, extraversion personality was a protective factor of elevated $\mathrm{BP}(P=0.03)$.

\section{The relationship of MS components value with QoL and personality scores}

The results obtained after adjustment for age, sex, region, foetal weight of pregnancy week and mother's education level, the association of MS components in 2014 with QoL and personality traits in 2019 are shown in Table 3. Domain scores of QoL of self-satisfaction $(P=0.02)$, PAA and factor score of living environment (all $P<0.01)$, as well as extraversion traits $(P<0.01)$ were inversely correlated with WC in 2014 , while neuroticism traits $(P=0.02)$ were positively correlated with WC. Elevated SBP in childhood was positively correlated with the domain score of physical feeling $(P=0.04)$ and factor score of physical and mental health $(P=0.02)$, and DBP in childhood was inversely correlated with domain score of PAA $(P=0.01)$ and extraversion personality $(P=0.05)$. In addition, higher HDL in childhood was predictive of higher domain scores of negative emotion $(P=0.02)$, higher factor scores of physical and mental health $(P=0.04)$, and higher score of extraversion traits $(P=0.04)$. Elevated FBG in childhood was positively correlated with domain score of activity opportunity $(P=0.05)$.

The linear relationship of QoL and personality traits with MS component levels in 2019 is shown in Table 3. After adjusting for age, sex, region, foetal weight of pregnancy week and mother's education level, the QoL domain score of companionship, PAA, factor score of living environment, total score of QoL, and extraversion personality score were negatively correlated with WC (all $P<0.01$ ). The domain scores of physical feeling, other domain, factor scores of physical 
and mental health and QoL satisfaction were positively correlated with both SBP and DBP levels, and domain scores of self-satisfaction, attitude towards doing homework, and factor score of total QoL score were positively correlated with DBP level. In contrast, extraversion personality scores were negatively correlated with SBP level $(P<0.01)$, and neuroticism personality score was also negatively correlated with DBP level $(P=0.03)$. The QoL domain scores of selfsatisfaction, relationship of teacher and pupil, PAA, negative emotion, and the factor scores of psychosocial, physical and mental health, living environment, quality of life satisfaction and the total score of QoL, and extraversion personality scores were positively correlated with TG. In addition, the domain scores of PAA, learning ability and extraversion trait score were positively correlated with HDL-C (all $P<0.05$ or $P<0.01$ ). The QoL domain score of physical feeling was borderline negatively correlated with FBG $(P=0.05)$.

The correlation of QoL and personality scores with MS components in the sub-group analyses is shown in Table 3. The results showed that PAA and living environment were negatively correlated with WC (all $P<0.01$ ), and physical feeling and attitude towards doing homework were positively correlated with DBP (all $P<0.05)$. Moreover, PAA, living environment, psychosocial score and total score of QoL were negatively correlated with TGs. Living environment was negatively correlated with FBG. Furthermore, a higher extraversion score was a protective factor for WC $(P=0.04), \operatorname{SBP}(P<0.01)$ and TGs $(P=0.035)$

\section{Relationship of QoL and personality traits scores with MS and MS score in 2019}

In the multivariable logistic regression model (Table 4) (adjusted for sex, age, region, foetal weight of pregnancy week and mother's education level), the results showed that QoL domain score of PAA was a protective factor for MS $(P<0.01)$. In addition, a high score of extraversion personality was a protective factor for MS even after adjusting for sex, age, region, foetal weight of pregnancy week and mother's education level $(P=0.05)$. However, the QoL score of "other" domain (picky-eating and surroundings) was positively correlated with $M S(P<0.05)$. In the full model, the QoL domain of other (picky-eating and surroundings) was positively correlated with MS $(P<0.01)$, and the living environment factor was negatively correlated with $M S(P<0.05)$.

The GLM (Table 5) also revealed that high score of PAA was protective factor of MS score $(P<0.01)$ and that a high factor score of living environment was negatively correlated with MS score before adjusting for covariables $(P=0.02)$.In contrast, a high QoL score of "other" domain was positively correlated with MS score $(P<0.01)$. A high PAA and extraversion personality score were significant protective factors of MS score in the sub-group analyses after adjustment for covariables $(P<0.05)$. In the full model, other (picky-eating and surroundings) domains were positively correlated with MS even after adjusting covariates $(P<0.01)$, and extraversion personality was a protective factor against MS in both total sample $(P<0.01)$ and sub-group $(P=0.03)$ analyses after adjustment for covariates.

\section{Discussion}

This study is the first prospective cohort study that revealed both the longitudinal and cross-sectional correlation between QoL and MS or MS components, as well as the association between personality traits and MS or MS components (in both 2014 and 2019) over an average 12-year follow-up from birth to adolescence in urban-rural areas. We observed that an increased prevalence of MS components (in both 2014 and 2019) and MS, as well as MS score was associated with QoL score and extraversion personality traits. The QoL domain score of PAA and extraversion personality score were independent protective factors for both MS and MS score.

Our study revealed that centrally obese children and adolescent were mainly negatively correlated with physical QoL scores, such as PAA and factor score of living environment, and a dose relationship was found. Our result was consistent with that of other studies[31-33], which showed that the obese population had lower health-related QoL (HRQoL) scores, as well as that weight loss would improve HRQoL[18, 34]. In our study, central obesity children even at a young age (6 8 years) would impact the QoL score in adolescents, suggesting that children with obesity should be given an effective intervention to improve HRQoL. In contrast, childhood and adolescent obesity were not significant correlated with mental aspects of QoL scores in our study, similar to the results of other studies[32]. In addition, this cohort study indicated that the BP level in childhood and adolescents was inversely correlated with physical QoL score of PAA as in adults[35], but it was positively correlated with mental QoL scores and total QoL scores; additionally, the mental QoL score results were not consistent with the results in adults with hypertension [36]. A study by Jing Sun et al [37] showed that a decrease in BP would improve the physical HRQoL score in adults with hypertension, but this conclusion is controversial. Attitude towards doing homework may impact the BP value in our study. Except for our study, there are no available data among children where the QoL was compared with elevated blood pressure, and the mechanism should be elucidated in future intervention study.

Research on the relationship between glycolipid indexes and QoL is limited. A study on adult cardiovascular disease illustrated that elevated TG level was inversely associated with both physical and QoL scores[35]. Our study was the first to reveal that elevated TG in childhood was not correlated with QoL scores in adolescents from a prospective perspective, but TG was negatively related to both physical (physical feeling and PAA) and mental (self-satisfaction, relationship of teacher and pupil and attitude towards doing homework) QoL domains scores, factor scores of physical and mental health and Living environment, and total QoL score from a cross-sectional perspective, and most of the correlations were significant in the health sub-group analyses. A previous study[38] of adulthood hypertension showed that elevated HDL-C was positively correlated with the EuroQol five-dimension, three-level (EQ-5D-3L) index and EuroQol visual analogue scale (EQ VAS) score. Accordingly, we found that increased HDL-C in childhood was positively correlated with the negative emotion domain score and physical and mental QoL factor scores, and was positively correlated with extraversion personality traits in children and adolescents. Additionally, HDL-C level in adolescents was positively correlated with physical (PAA) and mental ("Learning ability and attitude") QoL scores, while the correlation disappeared in the sub-group analyses. Our findings revealed that the QoL score regarding learning ability and attitude has a salient effect on lipid level in adolescents, but understanding the mechanism requires further research. In addition, FBG and HbA1c levels in Type 1 DM were negatively correlated with EQ-VAS (overall health status)[39], but our cohort study with an adolescent population showed that IFG in childhood was positively correlated with QoL score of activity opportunity. The controversial results could be explained by the different life style between healthy children and adults with DM, as well as by the different QoL questionnaires between adolescents and adults. 
However, a cross-sectional study showed that QoL scores were correlated with an increase in the components of MS, and the physical health domain of QoL had the most significant association [40]. In our study, we found that the PAA domain score and living environment factor score were protective factors of MS and MS score, but other (picky-eating and surroundings) domain scores were risk factors for MS and MS score even after adjustment for other covariates. Previous studies showed that health literacy training is a significant way to promote life quality [41], suggesting that health literacy training should be carried out in adolescents with a low QoL. To our knowledge, this is the first cohort study with a large sample size that explored the relationship of QoL with MS and MS score in adolescents.

Personality traits may be associated with MS, but the conclusion remains controversial, and few studies have been conducted in adult populations; no related cohort study has explored this relationship in adolescents. The results from Japanese adults [20] showed that the E score was positively correlated with TGs, FBG and MS components, and the P score was positively correlated with FBG. However, we found that the E score in adolescents was negatively correlated with MS, central obesity, and SBP and positively correlated with HDL, suggesting that the E score may be age dependent and have a different impact on lipid metabolism between adults and adolescents. A study by Evans, B. E. [42] reported that extraverted adolescents have less cortisol activity, which is associated with FBG and FI [43]. Therefore, extraversion traits may regulate glycolipid indexes through the hypothalamic-pituitary-adrenal axis pathway [42], which may impact MS by regulating the reactivity of the sympathetic nervous system (SNS) [44], and the SNS has potent effects on insulin secretion and sensitivity [45] and on lipid metabolism [46]. Adolescents with high N scores would be more prone to responding more strongly to a stressor, and our study did not find $\mathrm{N}$ to be correlated with MS, which was not consistent with the results of a study in adults [47].

Our study has some limitations that should be considered when interpreting the results. First, as this was a bidirectional cohort study, recall bias may exist for the prenatal variables. We checked the birth certificates to verify the birth weight, stature and gestational age. Second, data on GH and gestational diabetes were collected through a questionnaire, and recall bias existed. However, we collected the same perinatal information in both 2014 and 2019 independently to reduce recall bias and nonresponse. Finally, QoL and personality traits were collected in a cross-sectional manner in 2019, which makes it difficult to draw conclusions regarding causality relationships of QoL and personality traits with MS. Additionally, this study prospectively explored the relationship of MS components in childhood (in 2014) with the scores of QoL and personality traits in 2019.

In conclusion, the prevalence of MS was elevated among adolescents. Our finding add to the scarce research evidence regarding the relationship of QoL and personality traits with MS in children and adolescents, which will facilitate the generation of policy suggestions for health management institutes. In this study, we identified the relationship of QoL and personality traits with MS and MS components from both prospective and cross-sectional aspects after adjustment for other covariates. First, the PAA score was inversely correlated with MS and MS score, which suggested that establishment of comprehensive community, family and school intervention model to improve the PAA of children is essential for the control of adolescents MS. Second, the QoL score of other domains including picky-eating and surroundings was positively correlated with MS and MS score, indicating that health education including literacy training and health dietary habits should be implemented both at home and in school to improve life style. Finally, the extraversion personality trait was a protective factor of MS and MS score; therefore, primary prevention in childhood health should focus on cultivating children's extraversion personality. And Further studies should explore the effect of comprehensive intervention on the control of adolescent MS through improving the QoL and personality traits.

\section{Public Health Meaning}

In this study, we found the relationship of QoL and personality traits with MS and MS components both from prospective and cross-sectional aspects after adjusted other covariates. First, physical activity ability score was inversely correlated with MS and MS score, which suggested establish the comprehensive community, family and school intervention model to improve the physical activity ability of children is essential for the control of adolescents MS. Second, the QoL score of other domain including picky-eating and surroundings was positively correlated with MS and MS score, indicating the health education about health dietary habits should be implemented in both family and school to improve the life style. Finally, the extraversion personality traits was a protective factor of MS and MS score, therefore the primary prevention of childhood health should pay attention to cultivate children's extraversion personality.

\section{Abbreviations}

MS: metabolic syndrome; CVDs: cardiovascular diseases; TGs: triglycerides; HDL-C: high density lipoprotein cholesterol; SES: social economic status; QoL: quality of life; FBG: fasting blood-glucose; BMI: body mass index; GH: gestational hypertension; WC: waist circumference; BP: blood pressure; LDL: low density lipoprotein cholesterol; TC: total cholesterol; EPQ:

Eysenck's Personality Questionnaire; PAA: physical activity ability; E: extraversion; N: neuroticism; P: psychoticism; L: lie scales; IFG: impaired fasting glucose; LGA: large for gestational age; SGA: small for gestational age; IOM: the Institute of Medicine; SNK: Student-Newman-Keuls; GLM: generalized linear model; SBP: systolic blood pressure; DBP: diastolic blood pressure; HRQoL: health-related QoL; SNS: sympathetic nervous system

\section{Declarations}

\section{Ethics approval and consent to participate}

The Institutional Review Board at the Children's Hospital of Chongqing Medical University gave its approval for the study. Informed consent was provided by all subjects and parents/guardians. Informed consent of participate this study was provided by all subjects and parents/guardians.

\section{Consent for publication}

All authors critically reviewed and approved the publication of final paper. 
Availability of data and materials

Data are available from Xiaohua Liang (contact via xiaohualiang@hospital.cqmu.edu.cn or liangxiaohua666@sina.com).

Competing interests

Authors have no relevant conflict of interest to disclose.

Funding

This work was supported by National Key Research and Development Project of the Ministry of Science and Technology of the People's Republic of China (No.2017YFC0211705), Young Scientists Fund Program of the National Natural Science Foundation of China (No.81502826), School Funded Project of Chongqing Medical University (No.CQMUNCP0204), Young Scientists Fund Program of the Education Commission of Chongqing

(No.KJQN201900443), General Program of the China Postdoctoral Science Foundation (No.2014M562289), and Chongqing Postdoctoral Research Funded Projects (No.Xm2014129). The funders had no role in the study design, the data collection and analysis, the decision to publish, or the preparation of the manuscript.

\section{Authors' contributions}

$\mathrm{XH}$ conceived and designed the experiments; PZ and SQ performed the experiments; WF, GF, XT and LJ participated the physical measurement; XH wrote the paper; and all authors critically reviewed and approved the final paper. The authors would like to acknowledge the laboratory support of the Ministry of Education Key Laboratory of Child Development and Disorders and all the staff members of the 6 elementary schools in the two regions.

\section{Acknowledgements}

The authors would like to acknowledge the laboratory support of the Ministry of Education Key Laboratory of Child Development and Disorders and all the staff members of the 6 elementary schools in the two regions.

\section{References}

1. Koskinen JS, Kyto V, Juonala M, Viikari JSA, Nevalainen J, Kahonen M, Lehtimaki T, Hutri-Kahonen N, Laitinen T, Tossavainen P, et al: Childhood risk factors and carotid atherosclerotic plaque in adulthood: The Cardiovascular Risk in Young Finns Study. Atherosclerosis 2019, 293:18-25.

2. DeBoer MD, Gurka MJ, Woo JG, Morrison JA: Severity of Metabolic Syndrome as a Predictor of Cardiovascular Disease Between Childhood and Adulthood: The Princeton Lipid Research Cohort Study. J Am Coll Cardiol 2015, 66:755-757.

3. Johnson WD, Kroon JJ, Greenway FL, Bouchard C, Ryan D, Katzmarzyk PT: Prevalence of risk factors for metabolic syndrome in adolescents: National Health and Nutrition Examination Survey (NHANES), 2001-2006. Arch Pediatr Adolesc Med 2009, 163:371-377.

4. Li Y, Yang X, Zhai F, Kok FJ, Zhao W, Piao J, Zhang J, Cui Z, Ma G: Prevalence of the metabolic syndrome in Chinese adolescents. Br J Nutr 2008, 99:565570.

5. Magge SN, Goodman E, Armstrong SC, Committee On N, Section On E, Section On O: The Metabolic Syndrome in Children and Adolescents: Shifting the Focus to Cardiometabolic Risk Factor Clustering. Pediatrics 2017, 140.

6. Fadzlina AA, Harun F, Nurul Haniza MY, Al Sadat N, Murray L, Cantwell MM, Su TT, Majid HA, Jalaludin MY: Metabolic syndrome among 13 year old adolescents: prevalence and risk factors. BMC Public Health 2014, 14 Suppl 3:S7.

7. Lowe WL, Jr., Scholtens DM, Kuang A, Linder B, Lawrence JM, Lebenthal Y, McCance D, Hamilton J, Nodzenski M, Talbot O, et al: Hyperglycemia and Adverse Pregnancy Outcome Follow-up Study (HAPO FUS): Maternal Gestational Diabetes Mellitus and Childhood Glucose Metabolism. Diabetes Care 2019, 42:372-380.

8. He W, James SA, Merli MG, Zheng H: An increasing socioeconomic gap in childhood overweight and obesity in China. Am J Public Health 2014, 104:e1422.

9. Iglayreger HB, Peterson MD, Liu D, Parker CA, Woolford SJ, Sallinen Gafka BJ, Hassan F, Gordon PM: Sleep duration predicts cardiometabolic risk in obese adolescents. J Pediatr 2014, 164:1085-1090 e1081.

10. Saboya PP, Bodanese LC, Zimmermann PR, Gustavo AD, Assumpcao CM, Londero F: Metabolic syndrome and quality of life: a systematic review. Rev Lat Am Enfermagem 2016, 24:e2848.

11. Amiri P, Deihim T, Taherian R, Karimi M, Gharibzadeh S, Asghari-Jafarabadi M, Shiva N, Azizi F: Factors Affecting Gender Differences in the Association between Health-Related Quality of Life and Metabolic Syndrome Components: Tehran Lipid and Glucose Study. Plos One 2015, 10.

12. Vetter ML, Wadden TA, Lavenberg J, Moore RH, Volger S, Perez JL, Sarwer DB, Tsai AG: Relation of health-related quality of life to metabolic syndrome, obesity, depression and comorbid illnesses. Int J Obes (Lond) 2011, 35:1087-1094.

13. Lidfeldt J, Nyberg P, Nerbrand C, Samsioe G, Schersten B, Agardh CD: Socio-demographic and psychosocial factors are associated with features of the metabolic syndrome. The Women's Health in the Lund Area (WHILA) study. Diabetes Obes Metab 2003, 5:106-112.

14. Sarrafzadegan N, Gharipour M, Ramezani MA, Rabiei K, Zolfaghar B, Tavassoli AA, Boshtam M, Zarfeshani S, Khosravi A, Yousefi A: Metabolic syndrome and health-related quality of life in Iranian population. $J$ Res Med Sci 2011, 16:254-261.

15. Taylor TR, Dash C, Sheppard V, Makambi K, Ma X, Adams-Campbell LL: The effect of a randomized controlled physical activity trial on health related quality of life in metabolically unhealthy African-American women: FIERCE STUDY. Contemp Clin Trials 2018, 67:121-128.

Page $7 / 15$ 
16. Wu XY, Han LH, Zhang JH, Luo S, Hu JW, Sun K: The influence of physical activity, sedentary behavior on health-related quality of life among the general population of children and adolescents: A systematic review. PLOS One 2017, 12:e0187668.

17. Wu XY, Zhuang LH, Li W, Guo HW, Zhang JH, Zhao YK, Hu JW, Gao QQ, Luo S, Ohinmaa A, Veugelers PJ: The influence of diet quality and dietary behavior on health-related quality of life in the general population of children and adolescents: a systematic review and meta-analysis. Qual Life Res 2019 , 28:1989-2015.

18. Mollerup PM, Nielsen TRH, Bojsoe C, Kloppenborg JT, Baker JL, Holm JC: Quality of life improves in children and adolescents during a community-based overweight and obesity treatment. Qual Life Res 2017, 26:1597-1608.

19. Sagar R, Gupta T: Psychological Aspects of Obesity in Children and Adolescents. Indian J Pediatr 2018, 85:554-559.

20. Ohseto H, Ishikuro M, Kikuya M, Obara T, Igarashi Y, Takahashi S, Kikuchi D, Shigihara M, Yamanaka C, Miyashita M, et al: Relationships among personality traits, metabolic syndrome, and metabolic syndrome scores: The Kakegawa cohort study. J Psychosom Res 2018, 107:20-25.

21. Damian RI, Spengler M, Sutu A, Roberts BW: Sixteen going on sixty-six: A longitudinal study of personality stability and change across 50 years. $J$ Pers Soc Psychol 2019, 117:674-695.

22. Liang XH, Xiao L, Luo YT, Xu JP: Prevalence and risk factors of childhood hypertension from birth through childhood: a retrospective cohort study. Journal Of Human Hypertension 2020, 34:151-164.

23. Hanrong WU PL, Heng MENG Norn, Reliability and Validity of Children and Adolescents' QOL scale. Chinese Journal of School Health 2006, 27:18-21.

24. Yang Y: Rating Scales For Children's Developmental Behavior and Mental Health. People's Medical Publishing House co., Itd; 2016.

25. Wang Q, Yin J, Xu L, Cheng H, Zhao X, Xiang H, Lam HS, Mi J, Li M: Prevalence of metabolic syndrome in a cohort of Chinese schoolchildren: comparison of two definitions and assessment of adipokines as components by factor analysis. BMC Public Health 2013, 13:249.

26. Guansheng Ma CJ, Jun Ma,Jie Mi ,Rita YT Song,Feng Xiong,Weili Yan,Xiaoqi Hu, Yanping Li, Songming Du, Hongyun Fang, Jingxiong Jiang: Waist circumference reference values for screening cardiovascular risk factors in Chinese children and adolescents aged 7-18 years. Chinese Journal of Epidemiology 2010, 31:609-615.

27. Hui Fan YY, Jie Mi, on behalf of the Chinese Child Blood Pressure References Collaborative Group: Updating blood pressure references for Chinese children aged 3-17 years. Chinese Journal of Hypertension 2017, 25:428-435.

28. Mikolajczyk RT, Zhang J, Betran AP, Souza JP, Mori R, Gulmezoglu AM, Merialdi M: A global reference for fetal-weight and birthweight percentiles. Lancet 2011, 377:1855-1861

29. Hu L, Huang X, You C, Li J, Hong K, Li P, Wu Y, Wu Q, Wang Z, Gao R, et al: Prevalence of overweight, obesity, abdominal obesity and obesity-related risk factors in southem China. PLoS One 2017, 12:e0183934.

30. Johnson J, Clifton RG, Roberts JM, Myatt L, Hauth JC, Spong CY, Varner MW, Wapner RJ, Thorp JM, Jr., Mercer BM, et al: Pregnancy outcomes with weight gain above or below the 2009 Institute of Medicine guidelines. Obstet Gynecol 2013, 121:969-975.

31. Kesztyus D, Wirt T, Kobel S, Schreiber A, Kettner S, Dreyhaupt J, Kilian R, Steinacker JM, Komm mit in das gesunde Boot - Grundschule" - Research G: Is central obesity associated with poorer health and health-related quality of life in primary school children? Cross-sectional results from the BadenWurttemberg Study. BMC Public Health 2013, 13:260.

32. Kolotkin RL, Andersen JR: A systematic review of reviews: exploring the relationship between obesity, weight loss and health-related quality of life. Clin Obes 2017, 7:273-289.

33. Kesztyus D, Schreiber A, Kobel S, Wartha O, Kesztyus T, Kilian R, Steinacker JM, Study group "Join the Healthy Boat - Primary S: Illness and determinants of health-related quality of life in a cross-sectional sample of schoolchildren in different weight categories. Ger Med Sci 2014, 12:Doc04.

34. Poll FA, Miraglia F, D'Avila H F, Reuter CP, Mello ED: Impact of intervention on nutritional status, consumption of processed foods, and quality of life of adolescents with excess weight. J Pediatr (Rio J) 2019

35. Uchmanowicz I, Loboz-Grudzien K, Jankowska-Polanska B, Sokalski L: Influence of diabetes on health-related quality of life results in patients with acute coronary syndrome treated with coronary angioplasty. Acta Diabetol 2013, 50:217-225.

36. Adedapo AD, Akunne OO, Adedokun BO: Comparative assessment of determinants of health-related quality of life in hypertensive patients and normal population in south-west Nigeria. Int J Clin Pharmacol Ther 2015, 53:265-271.

37. Sun J, Buys N: Community-Based Mind-Body Meditative Tai Chi Program and Its Effects on Improvement of Blood Pressure, Weight, Renal Function, Serum Lipoprotein, and Quality of Life in Chinese Adults With Hypertension. Am J Cardiol 2015, 116:1076-1081.

38. Yan R, Gu HQ, Wang W, Ma L, Li W, Group CR: Health-related quality of life in blood pressure control and blood lipid-lowering therapies: results from the CHIEF randomized controlled trial. Hypertens Res 2019, 42:1561-1571.

39. Braga de Souza AC, Felicio JS, Koury CC, Neto JF, Mileo KB, Santos FM, Negrato CA, Motta AR, Silva DD, Arbage TP, et al: Health-related quality of life in people with type 1 Diabetes Mellitus: data from the Brazilian Type 1 Diabetes Study Group. Health Qual Life Outcomes 2015, 13:204.

40. Amiri P, Deihim T, Taherian R, Karimi M, Gharibzadeh S, Asghari-Jafarabadi M, Shiva N, Azizi F: Factors Affecting Gender Differences in the Association between Health-Related Quality of Life and Metabolic Syndrome Components: Tehran Lipid and Glucose Study. PLoS One 2015, $10: e 143167$.

41. Khandehroo M, Tavakoly Sany, Seyedeh, Oakley, D., Peyman, Nooshin: Health Literacy Intervention and quality of life in Menopausal Women: a Randomized Controlled Trial. International Journal of Health Promotion and Education 2020, 1.

42. Evans BE, Stam J, Huizink AC, Willemen AM, Westenberg PM, Branje S, Meeus W, Koot HM, van Lier PAC: Neuroticism and extraversion in relation to physiological stress reactivity during adolescence. Biol Psychol 2016, 117:67-79.

43. Park SB, Blumenthal JA, Lee SY, Georgiades A: Association of cortisol and the metabolic syndrome in Korean men and women. J Korean Med Sci 2011, 26:914-918.

Page 8/15 
44. Koolhaas JM, de Boer SF, Buwalda B, van Reenen K: Individual variation in coping with stress: a multidimensional approach of ultimate and proximate mechanisms. Brain Behav Evol 2007, 70:218-226.

45. Morton GJ, Muta K, Kaiyala KJ, Rojas JM, Scarlett JM, Matsen ME, Nelson JT, Acharya NK, Piccinini F, Stefanovski D, et al: Evidence That the Sympathetic Nervous System Elicits Rapid, Coordinated, and Reciprocal Adjustments of Insulin Secretion and Insulin Sensitivity During Cold Exposure. Diabetes 2017, 66:823-834.

46. Geerling JJ, Boon MR, Kooijman S, Parlevliet ET, Havekes LM, Romijn JA, Meurs IM, Rensen PC: Sympathetic nervous system control of triglyceride metabolism: novel concepts derived from recent studies. J Lipid Res 2014, 55:180-189.

47. van Doornen LJ, Orlebeke KF: Stress, personality and serum-cholesterol level. J Human Stress 1982, 8:24-29.

\section{Tables}


Table 1. General characteristics of adolescent QoL and personality traits with MS study

\begin{tabular}{|c|c|c|c|c|c|}
\hline \multirow[t]{2}{*}{ Variables } & \multirow[t]{2}{*}{ All } & \multicolumn{4}{|c|}{ Metabolic syndrome (MS) } \\
\hline & & No & $\begin{array}{l}1 \sim 2 \mathrm{MS} \\
\text { Components }\end{array}$ & Yes & $\mathrm{P}$ \\
\hline Sample size & 1961 & $1052(53.65 \%)$ & $817(41.66 \%)$ & $92(4.69 \%)$ & \\
\hline \multicolumn{6}{|l|}{ Region } \\
\hline Urban & 1467(74.81\%) & 829(78.80\%) & $576(70.50 \%)$ & $62(67.39 \%)$ & \multirow[t]{2}{*}{$<0.01$} \\
\hline Rural & $494(25.19 \%)$ & $223(21.20 \%)$ & $241(29.50 \%)$ & $30(32.61 \%)$ & \\
\hline Gender, male (n (\%)) & $1020(52.01 \%)$ & $554(52.66 \%)$ & $415(50.8 \%)$ & $51(55.43 \%)$ & 0.58 \\
\hline Age, y & $11.68 \pm 0.60$ & $11.65 \pm 0.60$ & $11.72 \pm 0.60$ & $11.75 \pm 0.60$ & 0.04 \\
\hline \multicolumn{6}{|l|}{ Anthropometric measures in 2014} \\
\hline Age, y & $7.26 \pm 0.59$ & $7.24 \pm 0.59$ & $7.28 \pm 0.58$ & $7.29 \pm 0.60$ & 0.33 \\
\hline Height, cm & $124.52 \pm 6.11$ & $123.67 \pm 5.86_{a}$ & $125.27 \pm 6.15_{b}$ & $127.57 \pm 6.72_{\mathrm{c}}$ & $<0.01$ \\
\hline Weight, kg & $25.92 \pm 5.58$ & $24.27 \pm 4.13_{\mathrm{a}}$ & $27.27 \pm 5.98_{b}$ & $32.65 \pm 7.61_{\mathrm{c}}$ & $<0.01$ \\
\hline $\mathrm{BMI}, \mathrm{kg} / \mathrm{m} 2$ & $16.59 \pm 2.53$ & $15.79 \pm 1.82_{\mathrm{a}}$ & $17.24 \pm 2.75 \mathrm{~b}$ & $19.84 \pm 3.09_{\mathrm{c}}$ & $<0.01$ \\
\hline Waist circumference, $\mathrm{cm}$ & $55.69 \pm 7.09$ & $53.59 \pm 5.55_{a}$ & $57.40 \pm 7.48 \mathrm{~b}$ & $64.23 \pm 8.46_{c}$ & $<0.01$ \\
\hline $\mathrm{SBP}, \mathrm{mmHg}$ & $100.6 \pm 8.94$ & $98.85 \pm 8.36_{a}$ & $102.14 \pm 9.04_{b}$ & $106.70 \pm 9.33_{\mathrm{c}}$ & $<0.01$ \\
\hline $\mathrm{DBP}, \mathrm{mmHg}$ & $62.68 \pm 7.76$ & $61.57 \pm 7.51_{\mathrm{a}}$ & $63.72 \pm 7.79_{\mathrm{b}}$ & $66.08 \pm 8.04_{\mathrm{c}}$ & $<0.01$ \\
\hline \multicolumn{6}{|l|}{ Anthropometric measures in 2019} \\
\hline Height, $\mathrm{cm}$ & $151.75 \pm 7.98$ & $150.22 \pm 7.89_{a}$ & $153.21 \pm 7.67_{\mathrm{b}}$ & $156.33 \pm 7.59_{\mathrm{c}}$ & $<0.01$ \\
\hline Weight, kg & $44.30 \pm 10.98$ & $39.63 \pm 7.69_{\mathrm{a}}$ & $48.58 \pm 11.24_{\mathrm{b}}$ & $59.62 \pm 11.30_{\mathrm{c}}$ & $<0.01$ \\
\hline $\mathrm{BMI}, \mathrm{kg} / \mathrm{m} 2$ & $19.07 \pm 3.76$ & $17.45 \pm 2.50_{a}$ & $20.58 \pm 4.01_{b}$ & $24.22 \pm 3.32_{\mathrm{C}}$ & $<0.01$ \\
\hline Waist circumference, $\mathrm{cm}$ & $65.83 \pm 10.03$ & $61.20 \pm 5.98 \mathrm{a}$ & $70.06 \pm 10.77_{b}$ & $81.18 \pm 8.26_{\mathrm{c}}$ & $<0.01$ \\
\hline Hip circumference, cm & $81.68 \pm 8.28$ & $78.45 \pm 6.49_{\mathrm{a}}$ & $84.68 \pm 8.41_{b}$ & $92.05 \pm 6.58_{\mathrm{c}}$ & $<0.01$ \\
\hline $\mathrm{SBP}, \mathrm{mmHg}$ & $105.71 \pm 9.49$ & $102.76 \pm 8.02 \mathrm{a}$ & $108.29 \pm 9.62_{b}$ & $116.62 \pm 9.36_{\mathrm{c}}$ & $<0.01$ \\
\hline $\mathrm{DBP}, \mathrm{mmHg}$ & $62.82 \pm 6.70$ & $61.40 \pm 5.87 \mathrm{a}$ & $63.98 \pm 7.07_{b}$ & $68.72 \pm 7.05_{\mathrm{c}}$ & $<0.01$ \\
\hline Puberty & $536(27.33 \%)$ & $267(25.38 \%)$ & $246(30.11 \%)$ & $23(25.00 \%)$ & 0.11 \\
\hline \multicolumn{6}{|l|}{ Serum biochemical indexes in 2014} \\
\hline $\mathrm{FBG}, \mathrm{mmol} / \mathrm{l}$ & $4.12 \pm 0.6$ & $4.07 \pm 0.59 \mathrm{a}$ & $4.17 \pm 0.58_{\mathrm{ab}}$ & $4.29 \pm 0.71_{b}$ & $<0.01$ \\
\hline $\mathrm{TC}, \mathrm{mmol} / \mathrm{l}$ & $3.51 \pm 0.72$ & $3.49 \pm 0.75$ & $3.54 \pm 0.68$ & $3.62 \pm 0.69$ & 0.25 \\
\hline $\mathrm{TG}, \mathrm{mmol} / \mathrm{l}$ & $0.91 \pm 0.53$ & $0.82 \pm 0.42_{\mathrm{a}}$ & $0.99 \pm 0.58_{b}$ & $1.36 \pm 0.78_{\mathrm{c}}$ & $<0.01$ \\
\hline $\mathrm{HDL}-\mathrm{C}, \mathrm{mmol} / \mathrm{l}$ & $1.26 \pm 0.27$ & $1.30 \pm 0.27 \mathrm{a}$ & $1.23 \pm 0.27 \mathrm{~b}$ & $1.10 \pm 0.22_{\mathrm{c}}$ & $<0.01$ \\
\hline LDL-C, $\mathrm{mmol} / \mathrm{l}$ & $1.73 \pm 0.56$ & $1.68 \pm 0.53 \mathrm{a}$ & $1.78 \pm 0.59 \mathrm{a}$ & $1.99 \pm 0.63_{b}$ & $<0.01$ \\
\hline Serum biochemical indexes in 201 & & & & & \\
\hline FBG, $\mathrm{mmol} / \mathrm{l}$ & $4.45 \pm 0.43$ & $4.45 \pm 0.38$ & $4.45 \pm 0.49$ & $4.50 \pm 0.51$ & 0.58 \\
\hline $\mathrm{TC}, \mathrm{mmol} / \mathrm{l}$ & $3.52 \pm 0.61$ & $3.53 \pm 0.57$ & $3.50 \pm 0.66$ & $3.47 \pm 0.62$ & 0.43 \\
\hline $\mathrm{TG}, \mathrm{mmol} / \mathrm{l}$ & $1.06 \pm 0.50$ & $0.83 \pm 0.20_{\mathrm{a}}$ & $1.26 \pm 0.55_{b}$ & $1.85 \pm 0.84_{\mathrm{c}}$ & $<0.01$ \\
\hline HDL-C, $\mathrm{mmol} / \mathrm{l}$ & $1.44 \pm 0.31$ & $1.55 \pm 0.28 \mathrm{a}$ & $1.34 \pm 0.28_{b}$ & $1.06 \pm 0.20_{\mathrm{C}}$ & $<0.01$ \\
\hline LDL-C, $\mathrm{mmol} / \mathrm{l}$ & $1.84 \pm 0.44$ & $1.81 \pm 0.42_{\mathrm{a}}$ & $1.86 \pm 0.46_{a}$ & $1.94 \pm 0.46_{\mathrm{b}}$ & $<0.01$ \\
\hline Metabolic syndrome components & & & & & \\
\hline Central obesity & $428(21.83 \%)$ & _- & $341(41.74 \%)$ & $87(94.57 \%)$ & $<0.01$ \\
\hline Elevated triglycerides & $499(25.45 \%)$ & - & $416(50.92 \%)$ & $83(90.22 \%)$ & $<0.01$ \\
\hline Reduced HDL-C & $182(9.28 \%)$ & - & $122(14.93 \%)$ & $60(65.22 \%)$ & $<0.01$ \\
\hline Elevated blood pressure & $192(9.79 \%)$ & - & $141(17.26 \%)$ & $51(55.43 \%)$ & $<0.01$ \\
\hline Impaired fasting glucose & $30(1.53 \%)$ & $\begin{array}{l}- \\
-\end{array}$ & $27(3.30 \%)$ & $3(3.26 \%)$ & $<0.01$ \\
\hline Perinatal measures & & & & & \\
\hline Maternal pre-conception obesity & & & & & \\
\hline Low weight & $1079(69.88 \%)$ & $579(70.70 \%)$ & $452(69.54 \%)$ & $48(64.00 \%)$ & 0.28 \\
\hline Normal weight & $317(20.53 \%)$ & $173(21.12 \%)$ & $126(19.38 \%)$ & $18(24.00 \%)$ & \\
\hline Overweight/Obesity & $148(9.59 \%)$ & $67(8.18 \%)$ & $72(11.08 \%)$ & $9(12.00 \%)$ & \\
\hline Pregnancy weight gain of mother & & & & & \\
\hline Below IOM guidelines & $473(30.85 \%)$ & $265(32.72 \%)$ & $182(28.04 \%)$ & $26(35.14 \%)$ & 0.15 \\
\hline Within IOM guidelines & $598(39.01 \%)$ & $319(39.38 \%)$ & $251(38.67 \%)$ & $28(37.84 \%)$ & \\
\hline Above IOM guidelines & $462(30.14 \%)$ & $226(27.90 \%)$ & $216(33.28 \%)$ & $20(27.03 \%)$ & \\
\hline Gestational age of mother, $y$ & $27.32 \pm 5.02$ & $27.23 \pm 4.90$ & $27.45 \pm 5.18$ & $27.21 \pm 5.03$ & 0.66 \\
\hline Gestational age of father, $y$ & $30.29 \pm 5.34$ & $30.26 \pm 5.28$ & $30.38 \pm 5.34$ & $29.87 \pm 6.04$ & 0.68 \\
\hline Birth weight, $\mathrm{g}$ & $3270.4 \pm 493.64$ & $3255.8 \pm 489.15$ & $3290.6 \pm 502.09$ & $3262 \pm 469.64$ & 0.34 \\
\hline Premature delivery & & & & & \\
\hline No & $1482(88.90 \%)$ & $801(89.90 \%)$ & $611(87.79 \%)$ & $70(87.50 \%)$ & 0.38 \\
\hline Yes & $185(11.10 \%)$ & $90(10.10 \%)$ & $85(12.21 \%)$ & $10(12.50 \%)$ & \\
\hline Fatal weight of pregnancy week & & & & & \\
\hline Appropriate for gestational age & $1097(68.18 \%)$ & $599(69.41 \%)$ & $444(66.37 \%)$ & $54(70.13 \%)$ & 0.04 \\
\hline Small for gestational age & $126(7.83 \%)$ & $79(9.15 \%)$ & $43(6.43 \%)$ & $4(5.19 \%)$ & \\
\hline Large for gestational age & $386(23.99 \%)$ & $185(21.44 \%)$ & $182(27.20 \%)$ & $19(24.68 \%)$ & \\
\hline Gestational hypertension & & & & & \\
\hline No & $1482(88.90 \%)$ & 801(89.90\%) & $611(87.79 \%)$ & $70(87.50 \%)$ & 0.65 \\
\hline Yes & $185(11.10 \%)$ & $90(10.10 \%)$ & $85(12.21 \%)$ & $10(12.50 \%)$ & \\
\hline Gestational diabetes & & & & & \\
\hline No & $1816(97.16 \%)$ & $980(97.32 \%)$ & $748(97.14 \%)$ & $88(95.65 \%)$ & 0.83 \\
\hline Yes & $53(2.84 \%)$ & $27(2.68 \%)$ & $22(2.86 \%)$ & $4(4.35 \%)$ & \\
\hline Smoke during pregnancy & & & & & \\
\hline No & $1845(98.51 \%)$ & 994(98.61\%) & $760(98.32 \%)$ & $91(98.91 \%)$ & 0.26 \\
\hline Yes & $28(1.49 \%)$ & $14(1.39 \%)$ & $13(1.68 \%)$ & $1(1.09 \%)$ & \\
\hline Birth with cesarean section & & & & & \\
\hline No & $1533(87.90 \%)$ & 816(87.55\%) & $649(88.90 \%)$ & $68(82.93 \%)$ & 0.19 \\
\hline Yes & $211(12.10 \%)$ & $116(12.45 \%)$ & $81(11.10 \%)$ & $14(17.07 \%)$ & \\
\hline Socioeconomic measures & & & & & \\
\hline Income, Yuan/year & & & & & \\
\hline$\sim 50,000$ & $603(32.40 \%)$ & $305(30.47 \%)$ & $267(34.59 \%)$ & $31(35.23 \%)$ & 0.42 \\
\hline
\end{tabular}




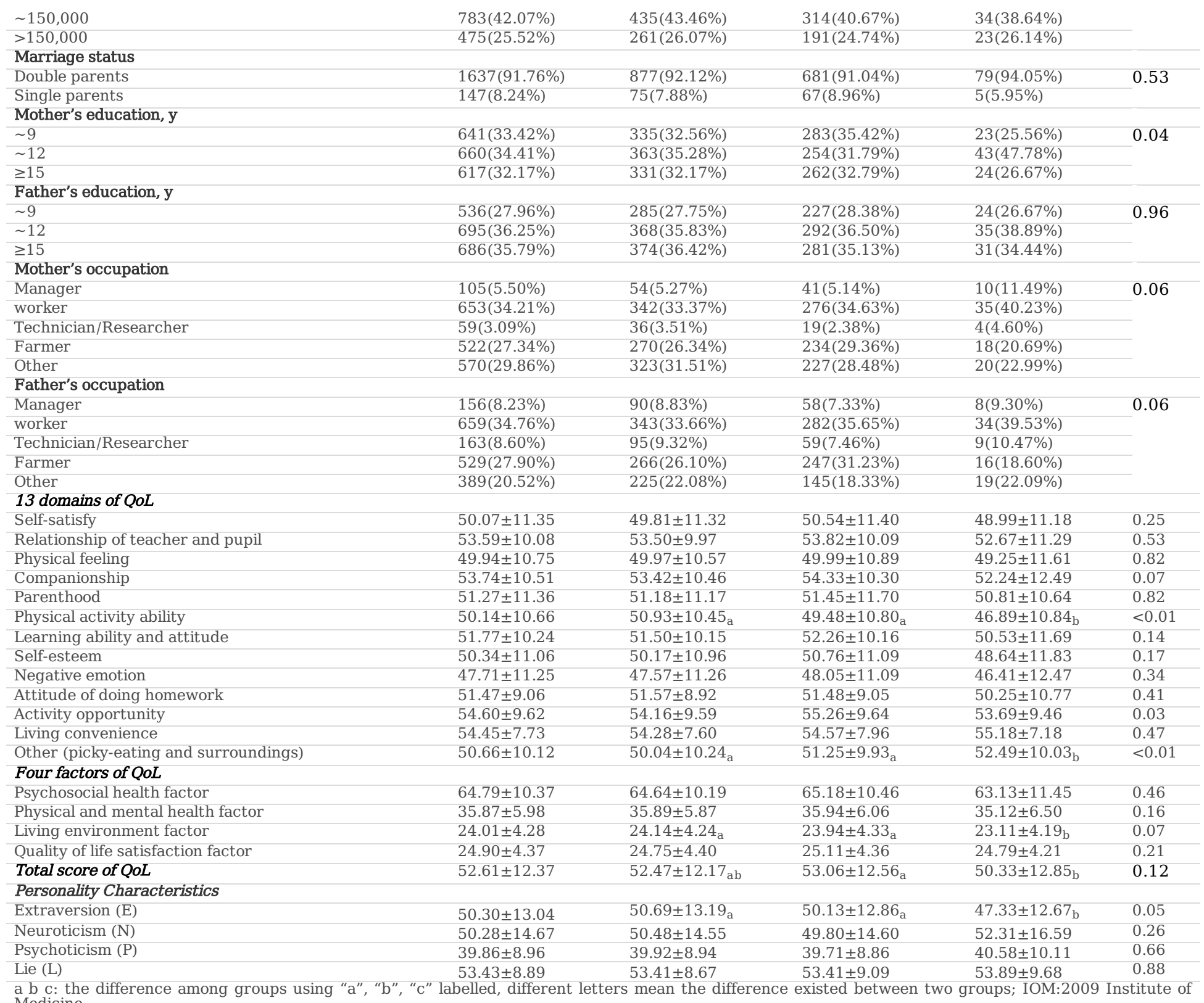

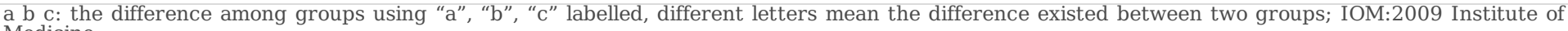
Medicine 
Table 2 Logistic regression analysis of the association of QoL and personality traits with adolescent MS components

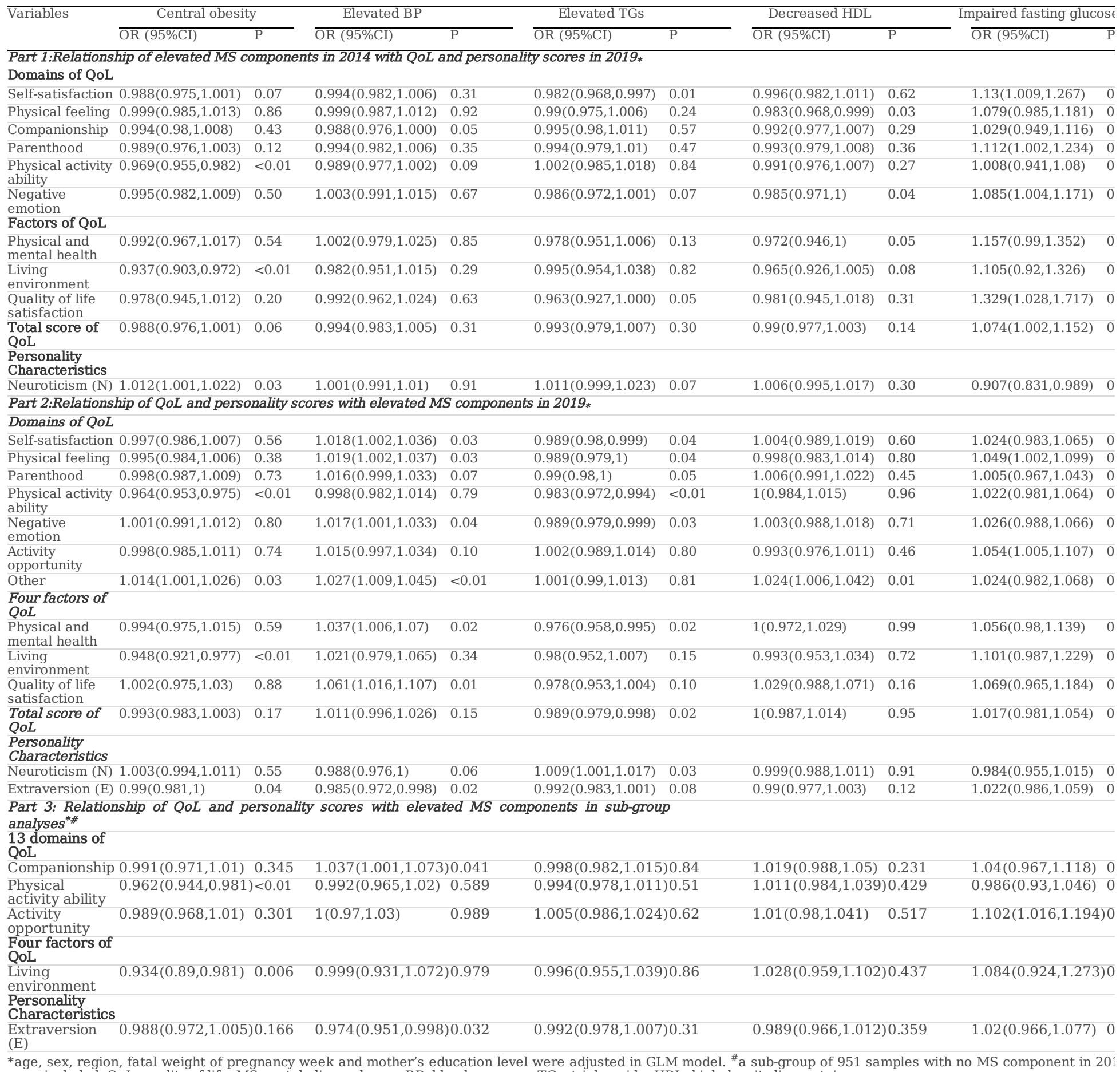

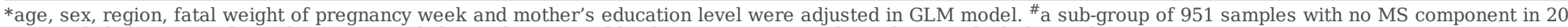
were included. QoL: quality of life, MS: metabolic syndrome, BP: blood pressure, TGs: triglyceride, HDL: high-density lipoprotein 
Table 3. The Correlation of QoL and Personality Characteristics of adolescent with MS components levels

\begin{tabular}{|c|c|c|c|c|c|c|c|c|c|}
\hline \multirow[t]{2}{*}{ Variables } & WC, $\mathrm{cm}$ & $\mathrm{SBP}, \mathrm{mmHg}$ & \multicolumn{2}{|c|}{$\mathrm{DBP}, \mathrm{mmHg}$} & \multicolumn{2}{|l|}{ TGs } & \multicolumn{2}{|l|}{ HDL } & \multirow{2}{*}{$\begin{array}{r}\text { FBG } \\
\text { B(SE) }\end{array}$} \\
\hline & $\begin{array}{cc}\mathrm{B}(\mathrm{SE}) & \mathrm{P}\end{array}$ & $\mathrm{B}(\mathrm{SE})$ & $\mathrm{B}(\mathrm{SE})$ & $\mathrm{P}$ & $\mathrm{B}(\mathrm{SE})$ & $\mathrm{P}$ & $\mathrm{B}(\mathrm{SE})$ & $\mathrm{P}$ & \\
\hline \multicolumn{10}{|c|}{ The association of MS components in 2014 with QoL and Personality Traits in 2019* } \\
\hline \multicolumn{10}{|c|}{$\begin{array}{l}13 \text { domains of } \\
\text { QoL }\end{array}$} \\
\hline Self-satisfaction & $-0.0385(0.0164) 0.02$ & $0.0238(0.0212) 0.26$ & $-0.0154(0.0186)$ & 0.41 & $-0.0019(0.0014)$ & 0.19 & $0.0008(0.0008)$ & 0.29 & $0.0015(0.0013)$ \\
\hline Physical feeling & $-0.0133(0.0176) 0.45$ & $0.0471(0.0227) 0.04$ & $0.0081(0.0197)$ & 0.68 & $0.0002(0.0016)$ & 0.91 & $0.0016(0.0008)$ & 0.06 & $-0.0012(0.0015)$ \\
\hline $\begin{array}{l}\text { Physical activity } \\
\text { ability }\end{array}$ & $-0.0881(0.0172)<0.01$ & $0.0072(0.0224) 0.75$ & $-0.0485(0.0195)$ & 0.01 & $-0.0018(0.0016)$ & 0.25 & $0.0012(0.0008)$ & 0.15 & $-0.0004(0.0015)$ \\
\hline $\begin{array}{l}\text { Negative } \\
\text { emotion }\end{array}$ & $-0.0118(0.0165) 0.48$ & $0.0397(0.0214) 0.06$ & $0.0127(0.0186)$ & 0.50 & $-0.0003(0.0014)$ & 0.81 & $0.0018(0.0008)$ & 0.02 & $0.0002(0.0013)$ \\
\hline $\begin{array}{l}\text { Activity } \\
\text { opportunity }\end{array}$ & $-0.0205(0.0195) 0.29$ & $-0.0014(0.0252) 0.96$ & $-0.0265(0.0219)$ & 0.23 & $-0.0009(0.0017)$ & 0.59 & $0.001(0.0009)$ & 0.27 & $0.0032(0.0016)$ \\
\hline \multicolumn{10}{|l|}{$\begin{array}{l}\text { Four factors of } \\
\text { QoL }\end{array}$} \\
\hline $\begin{array}{l}\text { Physical and } \\
\text { mental health }\end{array}$ & $-0.026(0.0317) 0.41$ & $0.0979(0.0409) 0.02$ & $0.0199(0.0357)$ & 0.58 & $-0.0004(0.0028)$ & 0.89 & $0.003(0.0015)$ & 0.04 & $-0.0007(0.0026)$ \\
\hline $\begin{array}{l}\text { Living } \\
\text { environment }\end{array}$ & $-0.1395(0.0451)<0.01$ & $0.0264(0.0585) 0.65$ & $-0.0862(0.0508)$ & 0.09 & $-0.0019(0.004)$ & 0.64 & $0.0035(0.0021)$ & 0.10 & $0.0035(0.0037)$ \\
\hline $\begin{array}{l}\text { Total score of } \\
\text { QoL }\end{array}$ & $-0.0279(0.0154) 0.07$ & $0.0349(0.0199) 0.08$ & $-0.0162(0.0173)$ & 0.35 & $-0.0012(0.0014)$ & 0.39 & $0.0013(0.0007)$ & 0.08 & $0.0008(0.0013)$ \\
\hline \multicolumn{10}{|l|}{$\begin{array}{l}\text { Personality } \\
\text { Traits }\end{array}$} \\
\hline Neuroticism (N) & $0.0294(0.0129) 0.02$ & $-0.0309(0.0167) 0.07$ & $-0.0038(0.0147)$ & 0.80 & $0.0005(0.0011)$ & 0.65 & $-0.0006(0.0006)$ & 0.36 & $-0.0008(0.001)$ \\
\hline Extraversion (E) & $-0.0418(0.0146)<0.01$ & $-0.0227(0.0191) 0.23$ & $-0.0329(0.0167)$ & 0.05 & $-0.0023(0.0013)$ & 0.08 & $0.0014(0.0007)$ & 0.04 & $0.0015(0.0012)$ \\
\hline \multicolumn{10}{|c|}{ The association of MS components in 2019 with QoL and Personality Traits in 2019* } \\
\hline \multicolumn{10}{|c|}{$\begin{array}{l}13 \text { domains of } \\
\text { QoL }\end{array}$} \\
\hline Self-satisfaction & $-0.0382(0.0214) 0.08$ & $0.0274(0.0199) 0.17$ & $0.0362(0.0146)$ & 0.01 & $-0.003(0.0011)$ & 0.01 & $0.0001(0.0007)$ & 0.91 & $0.0011(0.0009)$ \\
\hline $\begin{array}{l}\text { Relationship of } \\
\text { teacher and } \\
\text { pupil }\end{array}$ & $-0.0147(0.0245) 0.55$ & $0.0233(0.0227) 0.31$ & $0.0274(0.0167)$ & 0.10 & $-0.0025(0.0012)$ & 0.04 & $0.0005(0.0008)$ & 0.56 & $-0.0002(0.0011)$ \\
\hline Physical feeling & $-0.0174(0.0226) 0.44$ & $0.0431(0.021) \quad 0.04$ & $0.0551(0.0154)$ & $<0.01$ & $-0.0022(0.0011)$ & 0.05 & $0.0012(0.0007)$ & 0.10 & $0.002(0.001)$ \\
\hline Companionship & $-0.0593(0.0231) 0.01$ & $0.0033(0.0215) 0.88$ & $0.0141(0.0158)$ & 0.37 & $-0.0016(0.0012)$ & 0.16 & $-0.0001(0.0007)$ & 0.87 & $-0.0004(0.001)$ \\
\hline $\begin{array}{l}\text { Physical activity } \\
\text { ability }\end{array}$ & $-0.1658(0.0225)<0.01$ & $-0.0056(0.0212) 0.79$ & $-0.0296(0.0156)$ & 0.06 & $-0.0047(0.0011)$ & $<0.01$ & $0.0015(0.0007)$ & 0.04 & $0.0002(0.001)$ \\
\hline $\begin{array}{l}\text { Learning ability } \\
\text { and attitude }\end{array}$ & $-0.0097(0.024) \quad 0.69$ & $0.0006(0.0223) 0.98$ & $0.0312(0.0164)$ & 0.06 & $-0.0021(0.0012)$ & 0.07 & $0.0023(0.0008)$ & $<0.01$ & $0.0003(0.001)$ \\
\hline $\begin{array}{l}\text { Negative } \\
\text { emotion }\end{array}$ & $-0.0023(0.0217) 0.92$ & $0.0247(0.0202) 0.22$ & $0.0235(0.0148)$ & 0.11 & $-0.0024(0.0011)$ & 0.03 & $0.0005(0.0007)$ & 0.45 & $0.001(0.0009)$ \\
\hline $\begin{array}{l}\text { Attitude towards } \\
\text { doing homework }\end{array}$ & $0.0129(0.0273) 0.64$ & $0.0415(0.0253) 0.10$ & $0.0595(0.0185)$ & $<0.01$ & $-0.0025(0.0014)$ & 0.06 & $0.0009(0.0009)$ & 0.30 & $-0.0007(0.0012)$ \\
\hline $\begin{array}{l}\text { Other (picky- } \\
\text { eating and } \\
\text { surroundings) }\end{array}$ & $0.0624(0.0244) 0.01$ & $0.072(0.0226)<0.01$ & $0.0627(0.0166)$ & $<0.01$ & $0.0004(0.0012)$ & 0.73 & $-0.0003(0.0008)$ & 0.72 & $-0.0001(0.0011)$ \\
\hline \multicolumn{10}{|l|}{$\begin{array}{l}\text { Four factors of } \\
\text { QoL }\end{array}$} \\
\hline Psychosocial & $-0.0431(0.0242) 0.08$ & $0.0082(0.0225) 0.72$ & $0.0296(0.0165)$ & 0.07 & $-0.0025(0.0012)$ & 0.04 & $0.001(0.0008)$ & 0.20 & $-0.0001(0.001)$ \\
\hline $\begin{array}{l}\text { Physical and } \\
\text { mental health }\end{array}$ & $-0.0146(0.0412) 0.72$ & $0.0809(0.0382) 0.03$ & $0.0981(0.028)$ & $<0.01$ & $-0.0052(0.0021)$ & 0.01 & $0.0019(0.0013)$ & 0.14 & $0.0024(0.0018)$ \\
\hline $\begin{array}{l}\text { Living } \\
\text { environment }\end{array}$ & $-0.2627(0.0588)<0.01$ & $0.004(0.0549) \quad 0.94$ & $0.0004(0.0403)$ & 0.99 & $-0.0086(0.0029)$ & $<0.01$ & $0.0033(0.0019)$ & 0.08 & $0.0002(0.0025)$ \\
\hline $\begin{array}{l}\text { Quality of life } \\
\text { satisfaction }\end{array}$ & $-0.0383(0.0558) 0.49$ & $0.11(0.0517) \quad 0.03$ & $0.124(0.0379)$ & $<0.01$ & $-0.0062(0.0028)$ & 0.03 & $-0.0001(0.0018)$ & 0.96 & $0.0023(0.0024)$ \\
\hline $\begin{array}{l}\text { Total score of } \\
\text { QoL }\end{array}$ & $-0.0407(0.0201) 0.04$ & $0.0199(0.0186) 0.28$ & $0.0329(0.0136)$ & 0.02 & $-0.0032(0.001)$ & $<0.01$ & $0.001(0.0006)$ & 0.14 & $0.0004(0.0009)$ \\
\hline \multicolumn{10}{|l|}{$\begin{array}{l}\text { Personality } \\
\text { Traits }\end{array}$} \\
\hline Neuroticism (N) & $0.0317(0.0169) 0.06$ & $-0.02(0.0157) \quad 0.20$ & $-0.0246(0.0114)$ & 0.03 & $0.0014(0.0008)$ & 0.09 & $-0.0003(0.0005)$ & 0.60 & $-0.0007(0.0007)$ \\
\hline Extraversion (E) & $-0.0706(0.0193)<0.01$ & $-0.0577(0.018)<0.01$ & $-0.0241(0.0131)$ & 0.07 & $-0.0027(0.001)$ & 0.01 & $0.0015(0.0006)$ & 0.02 & $0.0004(0.0008)$ \\
\hline \multicolumn{10}{|c|}{ Part 3: Relationship of QoL and personality scores with MS components in sub-group analyses* } \\
\hline \multicolumn{10}{|c|}{$\begin{array}{l}13 \text { domains of } \\
\text { QoL }\end{array}$} \\
\hline Physical feeling & $-0.0377(0.0281) 0.181$ & $-0.0019(0.0292) 0.948$ & $0.0433(0.0216)$ & 0.045 & $-0.0012(0.0016)$ & 0.453 & $-0.0004(0.001)$ & 0.669 & $0.0009(0.0014)$ \\
\hline $\begin{array}{l}\text { Physical } \\
\text { activity ability }\end{array}$ & $-0.1267(0.027)<0.01$ & $0.0282(0.0284) 0.322$ & $-0.0214(0.0211)$ & 0.31 & $-0.0038(0.0016)$ & 0.015 & $0.0002(0.001)$ & 0.825 & $-0.0007(0.0013)$ \\
\hline $\begin{array}{l}\text { Learning } \\
\text { ability and } \\
\text { attitude }\end{array}$ & $-0.0381(0.0292) 0.192$ & $0.0112(0.0303) 0.711$ & $0.0415(0.0224)$ & 0.064 & $-0.0032(0.0017)$ & 0.054 & $0.0012(0.0011)$ & 0.272 & $-0.0005(0.0014)$ \\
\hline $\begin{array}{l}\text { Negative } \\
\text { emotion }\end{array}$ & $0.0092(0.0264) 0.728$ & $0.0016(0.0275) 0.953$ & $0.0008(0.0203)$ & 0.967 & $-0.0029(0.0015)$ & 0.055 & $-0.0006(0.001)$ & 0.515 & $-0.0002(0.0013)$ \\
\hline $\begin{array}{l}\text { Attitude } \\
\text { towards doing } \\
\text { homework }\end{array}$ & $-0.021(0.0325) 0.518$ & $0.0102(0.0338) 0.764$ & $0.0594(0.0249)$ & 0.017 & $-0.0014(0.0019)$ & 0.455 & $-0.0006(0.0012)$ & 0.627 & $-0.0012(0.0016)$ \\
\hline $\begin{array}{l}\text { Living } \\
\text { convenience }\end{array}$ & $-0.0171(0.0386) 0.657$ & $-0.0253(0.0401) 0.529$ & $-0.0171(0.0297)$ & 0.564 & $-0.005(0.0022)$ & 0.024 & $0(0.0014)$ & 0.991 & $-0.0041(0.0019)$ \\
\hline \multicolumn{10}{|c|}{$\begin{array}{l}\text { Four factors of } \\
\text { QoL }\end{array}$} \\
\hline Psychosocial & $-0.0435(0.0299) 0.146$ & $0.0137(0.0309) 0.658$ & $0.0287(0.023)$ & 0.212 & $-0.0034(0.0017)$ & 0.049 & $-0.0004(0.0011)$ & 0.720 & $-0.0007(0.0014)$ \\
\hline $\begin{array}{l}\text { Living } \\
\text { environment }\end{array}$ & $-0.2255(0.0694) 0.001$ & $0.0054(0.0726) 0.941$ & $-0.0359(0.0538)$ & 0.504 & $-0.0099(0.004)$ & 0.014 & $-0.0021(0.0026)$ & 0.421 & $-0.0037(0.0034)$ \\
\hline $\begin{array}{l}\text { Total score of } \\
\text { QoL }\end{array}$ & $-0.045(0.0248) 0.07$ & $0.0043(0.0257) 0.868$ & $0.02(0.019)$ & 0.295 & $-0.0038(0.0014)$ & 0.008 & $-0.0007(0.0009)$ & 0.446 & $-0.0007(0.0012)$ \\
\hline \multicolumn{10}{|c|}{ Personality } \\
\hline $\begin{array}{l}\text { Extraversion } \\
(\mathrm{E})\end{array}$ & $-0.0513(0.0245) 0.037$ & $-0.0678(0.0256) 0.008$ & $-0.0138(0.019)$ & 0.467 & $-0.003(0.0014)$ & 0.035 & $0.0007(0.0009)$ & 0.465 & $-0.0007(0.0012)$ \\
\hline
\end{tabular}

SBP: systolic blood pressure, DBP: diastolic blood pressure, TGs: triglyceride, HDL: high-density lipoprotein, FBG: fasting blood-glucose, ns: non-significance 
Table 4 Logistic regression analysis the relationship of QoL and personality traits with adolescent MS

\begin{tabular}{|c|c|c|c|c|c|c|}
\hline \multirow[t]{2}{*}{ Variables } & \multicolumn{3}{|c|}{ MS } & \multicolumn{3}{|c|}{$\mathrm{MS} *$} \\
\hline & $\overline{\mathrm{B}}$ & OR $(95 \% C I)$ & $\mathrm{P}$ & $\mathrm{B}$ & OR $(95 \%$ CI $)$ & $\mathrm{P}$ \\
\hline \multicolumn{7}{|l|}{13 domains of $Q o L$} \\
\hline Self-satisfaction & -0.006 & $0.994(0.976,1.012)$ & 0.51 & -0.006 & $0.994(0.975,1.012)$ & 0.50 \\
\hline Relationship of teacher and pupil & -0.008 & $0.992(0.972,1.013)$ & 0.45 & -0.008 & $0.992(0.971,1.013)$ & 0.43 \\
\hline Physical feeling & -0.006 & $0.994\left(0.97^{1} 5,1.013\right)$ & 0.54 & -0.007 & $0.993(0.974,1.013)$ & 0.51 \\
\hline Companionship & -0.010 & $0.990(0.971,1.009)$ & 0.31 & -0.012 & $0.988(0.969,1.007)$ & 0.23 \\
\hline Parenthood & -0.003 & $0.997(0.978,1.016)$ & 0.76 & -0.002 & $0.998(0.979,1.018)$ & 0.88 \\
\hline Physical activity ability & -0.035 & $0.965(0.946,0.985)$ & $<0.01$ & -0.034 & $0.966(0.947,0.986)$ & $<0.01$ \\
\hline Learning ability and attitude & -0.009 & $0.991(0.971,1.011)$ & 0.38 & -0.010 & $0.990(0.969,1.011)$ & 0.34 \\
\hline Self-esteem & -0.013 & $0.987(0.968,1.007)$ & 0.20 & -0.014 & $0.986(0.966,1.006)$ & 0.16 \\
\hline Negative emotion & -0.009 & $0.991(0.973,1.010)$ & 0.35 & -0.009 & $0.992(0.973,1.010)$ & 0.37 \\
\hline Attitude towards doing homework & -0.015 & $0.985(0.964,1.007)$ & 0.18 & -0.017 & $0.983(0.962,1.005)$ & 0.14 \\
\hline Activity opportunity & -0.005 & $0.995(0.973,1.017)$ & 0.65 & -0.007 & $0.993(0.971,1.015)$ & 0.53 \\
\hline Living convenience & 0.017 & $1.017(0.987,1.048)$ & 0.28 & 0.014 & $1.014(0.984,1.045)$ & 0.36 \\
\hline Other (picky-eating and surroundings) & 0.024 & $1.024(1.003,1.046)$ & 0.03 & 0.029 & $1.029(1.007,1.052)$ & 0.01 \\
\hline \multicolumn{7}{|l|}{ Four factors of $Q o L$} \\
\hline Psychosocial & -0.014 & $0.986(0.967,1.006)$ & 0.18 & -0.012 & $0.988(0.967,1.009)$ & 0.25 \\
\hline Physical and mental health & -0.021 & $0.979(0.945,1.014)$ & 0.23 & -0.020 & $0.980(0.946,1.015)$ & 0.26 \\
\hline Living environment & -0.056 & $0.946(0.900,0.993)$ & 0.03 & -0.050 & $0.952(0.904,1.002)$ & 0.06 \\
\hline Quality of life satisfaction & 0.002 & $1.002(0.954,1.052)$ & 0.93 & 0.008 & $1.008(0.959,1.060)$ & 0.76 \\
\hline Total score of $Q o L$ & -0.014 & $0.986(0.970,1.003)$ & 0.11 & -0.015 & $0.985(0.968,1.002)$ & 0.09 \\
\hline \multicolumn{7}{|l|}{ Personality Characteristics } \\
\hline Neuroticism (N) & 0.008 & $1.008(0.994,1.023)$ & 0.26 & 0.008 & $1.008(0.993,1.023)$ & 0.28 \\
\hline Psychoticism (P) & 0.008 & $1.008(0.985,1.031)$ & 0.51 & 0.008 & $1.008(0.985,1.032)$ & 0.48 \\
\hline Extraversion (E) & -0.018 & $0.982(0.967,0.997)$ & 0.02 & -0.016 & $0.984(0.968,1.000)$ & 0.05 \\
\hline \multicolumn{7}{|l|}{ Full model } \\
\hline Physical activity ability & -0.012 & $0.988(0.966,1.009)$ & 0.259 & -0.014 & $0.986(0.965,1.008)$ & 0.22 \\
\hline Other (picky-eating and surroundings) & 0.045 & $1.046(1.02,1.073)$ & $<0.001$ & 0.047 & $1.048(1.022,1.075)$ & $<0.001$ \\
\hline Living environment & -0.077 & $0.926(0.87,0.986)$ & 0.017 & -0.071 & $0.932(0.873,0.994)$ & 0.032 \\
\hline Extraversion (E) & -0.012 & $0.988(0.971,1.006)$ & 0.193 & -0.011 & $0.989(0.971,1.007)$ & 0.233 \\
\hline
\end{tabular}

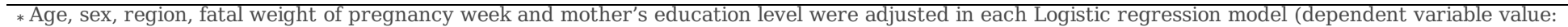

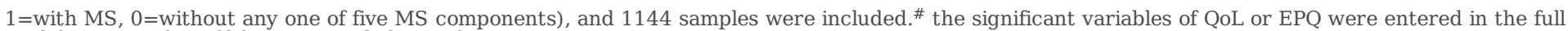
model. QoL: quality of life, MS: metabolic syndrome

Mollerup PM, Nielsen TRH, Bojsoe C, Kloppenborg JT, Baker JL, Holm JC. Quality of life improves in children and adolescents during a community-based overweight and obesity treatment. Quality of life research : an international journal of quality of life aspects of treatment, care and rehabilitation. 2017;26:15971608

Table 5 GLM analysis the association of QoL and personality traits with adolescent MS score

\begin{tabular}{|c|c|c|c|c|c|c|c|c|c|}
\hline \multirow[t]{2}{*}{ Variables } & \multicolumn{3}{|c|}{ MS } & \multicolumn{3}{|c|}{ MS* } & \multicolumn{3}{|c|}{ MS sub-group $\#$} \\
\hline & $\overline{\mathrm{B}}$ & StdErr & $\mathrm{P}$ & $\bar{B}$ & StdErr & $\mathrm{P}$ & $\mathrm{B}$ & StdErr & $\mathrm{P}$ \\
\hline \multicolumn{10}{|l|}{13 domains of QoL } \\
\hline Self-satisfaction & 0.001 & 0.002 & 0.73 & 0.001 & 0.002 & 0.82 & 0.002 & 0.002 & 0.333 \\
\hline Relationship of teacher and pupil & -0.002 & 0.002 & 0.38 & -0.001 & 0.002 & 0.48 & -0.002 & 0.003 & 0.505 \\
\hline Physical feeling & -0.001 & 0.002 & 0.76 & -0.001 & 0.002 & 0.65 & 0.001 & 0.002 & 0.965 \\
\hline Companionship & 0.001 & 0.002 & 0.87 & 0.001 & 0.002 & 0.94 & 0.002 & 0.002 & 0.463 \\
\hline Parenthood & 0.001 & 0.002 & 0.83 & 0.001 & 0.002 & 0.95 & -0.001 & 0.002 & 0.648 \\
\hline Physical activity ability & -0.008 & 0.002 & $<0.01$ & -0.008 & 0.002 & $<0.01$ & -0.005 & 0.002 & 0.024 \\
\hline Learning ability and attitude & 0.001 & 0.002 & 0.94 & 0.001 & 0.002 & 0.86 & -0.002 & 0.003 & 0.435 \\
\hline Self-esteem & -0.001 & 0.002 & 0.61 & -0.001 & 0.002 & 0.51 & -0.003 & 0.002 & 0.185 \\
\hline Negative emotion & 0.001 & 0.002 & 0.58 & 0.001 & 0.002 & 0.67 & 0.001 & 0.002 & 0.977 \\
\hline Attitude towards doing homework & -0.002 & 0.002 & 0.30 & -0.003 & 0.002 & 0.15 & -0.001 & 0.003 & 0.821 \\
\hline Activity opportunity & 0.003 & 0.002 & 0.11 & 0.003 & 0.002 & 0.18 & 0.001 & 0.003 & 0.688 \\
\hline Living convenience & 0.001 & 0.003 & 0.66 & 0.001 & 0.003 & 0.88 & -0.001 & 0.003 & 0.769 \\
\hline Other (picky-eating and surroundings) & 0.006 & 0.002 & $<0.01$ & 0.007 & 0.002 & $<0.01$ & 0.003 & 0.003 & 0.304 \\
\hline \multicolumn{10}{|l|}{ Four factors of $Q o L$} \\
\hline Psychosocial & -0.002 & 0.002 & 0.38 & -0.001 & 0.002 & 0.66 & -0.001 & 0.003 & 0.576 \\
\hline Physical and mental health & -0.001 & 0.003 & 0.68 & -0.001 & 0.003 & 0.66 & 0.001 & 0.005 & 0.981 \\
\hline Living environment & -0.011 & 0.005 & 0.02 & -0.007 & 0.005 & 0.12 & -0.006 & 0.006 & 0.310 \\
\hline Quality of life satisfaction & 0.005 & 0.005 & 0.28 & 0.006 & 0.005 & 0.19 & 0.007 & 0.006 & 0.254 \\
\hline Total score of $Q o L$ & -0.001 & 0.002 & 0.46 & -0.001 & 0.002 & 0.40 & -0.001 & 0.002 & 0.502 \\
\hline \multicolumn{10}{|l|}{ Personality Characteristics } \\
\hline Neuroticism (N) & 0.001 & 0.001 & 0.93 & 0.001 & 0.001 & 0.93 & 0.001 & 0.002 & 0.821 \\
\hline Psychoticism (P) & 0.001 & 0.002 & 0.99 & 0.001 & 0.002 & 0.78 & 0.002 & 0.003 & 0.575 \\
\hline Extraversion (E) & -0.004 & 0.002 & 0.01 & -0.003 & 0.002 & 0.06 & -0.005 & 0.002 & 0.032 \\
\hline \multicolumn{10}{|l|}{ Full model } \\
\hline Physical activity ability & -0.001 & 0.002 & 0.575 & -0.003 & 0.002 & 0.131 & 0.001 & 0.003 & 0.672 \\
\hline Other (picky-eating and surroundings) & 0.010 & 0.003 & $<0.001$ & 0.01 & 0.002 & $<0.001$ & - & -- & -- \\
\hline Living environment & -0.016 & 0.006 & 0.012 & -- & -- & -- & - & -- & -- \\
\hline Extraversion (E) & -0.005 & 0.002 & 0.008 & -0.006 & 0.002 & 0.001 & -0.005 & 0.002 & 0.029 \\
\hline
\end{tabular}

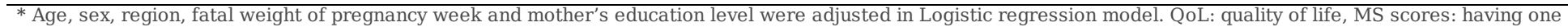
metabolic syndrome components markers one score. * including the samples who have no MS components in 2014 ( $\mathrm{n}=951$ ). 
Figures

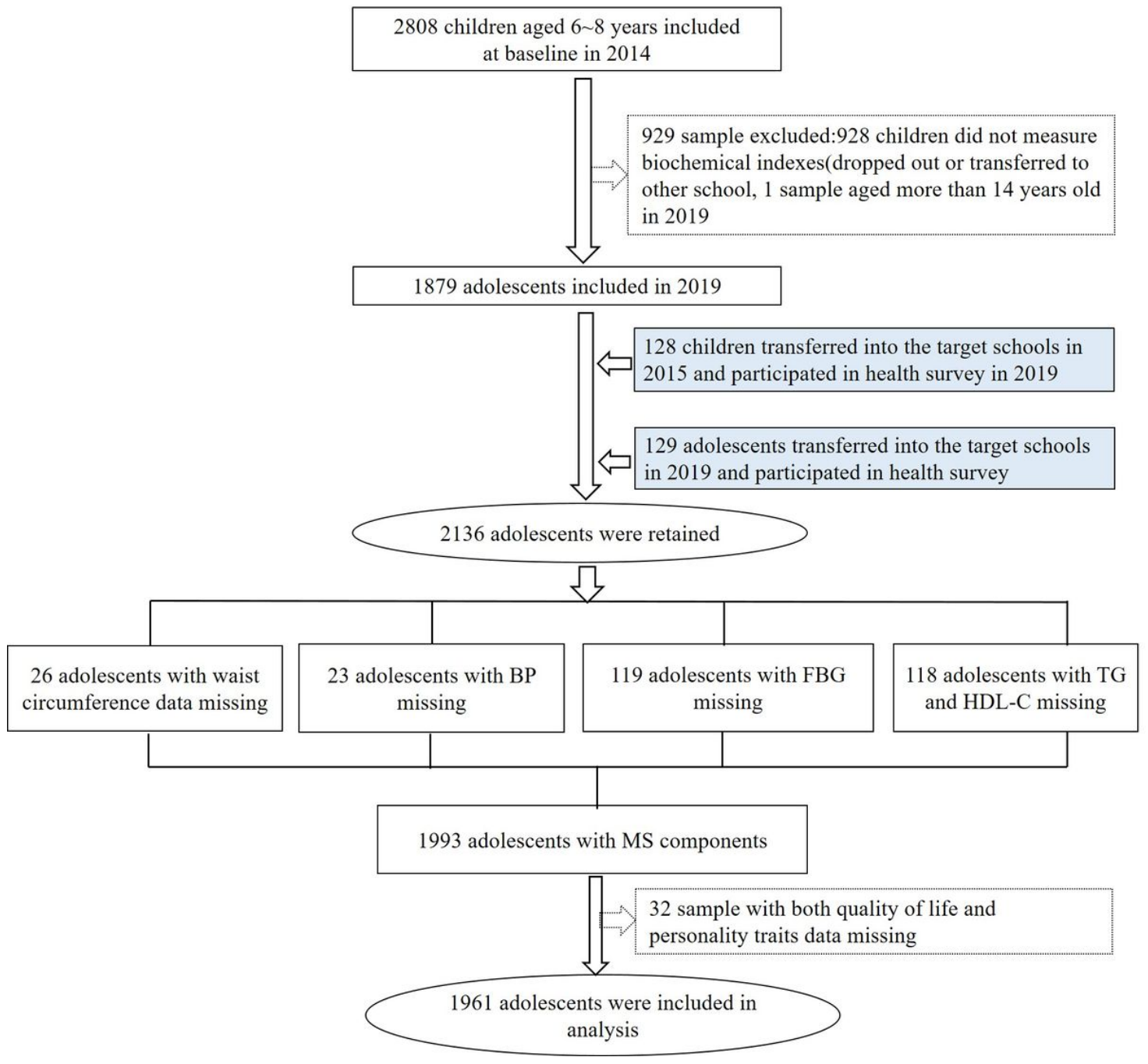

Figure 1

The flow chart of samples been included in the analyses

\section{Supplementary Files}

This is a list of supplementary files associated with this preprint. Click to download.

- supplementarytable1USE.docx

- supplementaryfigure1.tiff 